ANA MARIA VEIGA CLAUDIA REGINA NICHNIG CRISTINA SCHEIEE WOLFF JAR ZANDONA Oranzople

\title{
MUNDOS DE MULHERES NO BRASIL
}
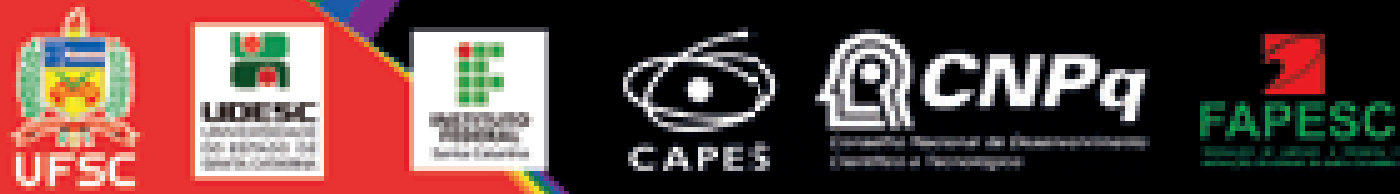
CAPrs sing

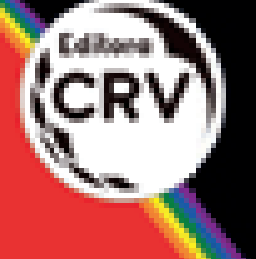



Ana Maria Veiga

Claudia Regina Nichnig

Cristina Scheibe Wolff

Jair Zandoná

(Organização)

\section{MUNDOS DE MULHERES NO BRASIL}

Editora CRV

Curitiba - Brasil

2019 
Copyright $(\mathcal{C}$ da Editora CRV

Editor-chefe: Railson Moura

Diagramação e Capa: Editora CRV

Revisão: Gerusa Bondan e Maria Isabel de Castro Lima

DADOS INTERNACIONAIS DE CATALOGAÇÃO NA PUBLICAÇÃO (CIP)

CATALOGAÇÃO NA FONTE

M954

Mundos de mulheres no Brasil / Ana Maria Veiga, Claudia Regina Nichnig, Cristina Scheibe Wolff, Jair Zandoná (organização) - Curitiba : CRV, 2019.

$550 \mathrm{p}$.

Bibliografia

ISBN 978-85-444-3129-0

DOI $10.24824 / 978854443129.0$

1. Ciências sociais. 2. Relações de gênero. 3. Feminismos. 4. Gênero. 5. Mulheres. I. Veiga, Ana Maria. org. II. Nichnig, Claudia Regina. org. III. Wolff, Cristina Scheibe. org. IV. Zandoná, Jair. org. V. Título. VI. Série.

CDD 305.42

Índice para catálogo sistemático

1. Mulheres 305.42

ESTA OBRA TAMBÉM ENCONTRA-SE DISPONÍVEL EM

FORMATO DIGITAL.

CONHEÇA E BAIXE NOSSO APLICATIVO!

DISPONIVEL NO

Google Play

Baixar na

App Store

2019

Foi feito o depósito legal conf. Lei 10.994 de 14/12/2004

Proibida a reprodução parcial ou total desta obra sem autorização da Editora CRV

Todos os direitos desta edição reservados pela: Editora CRV

Tel.: (41) 3039-6418 - E-mail: sac@editoracrv.com.br

Conheça os nossos lançamentos: www.editoracrv.com.br 


\section{Conselho Editorial: Comitê Científico:}

Aldira Guimarães Duarte Domínguez (UNB)

Andréia da Silva Quintanilha Sousa (UNIR/UFRN)

Antônio Pereira Gaio Júnior (UFRRJ)

Carlos Alberto Vilar Estêvão (UMINHO - PT)

Carlos Federico Dominguez Avila (Unieuro)

Carmen Tereza Velanga (UNIR)

Celso Conti (UFSCar)

Cesar Gerónimo Tello (Univer. Nacional

Três de Febrero - Argentina)

Eduardo Fernandes Barbosa (UFMG)

Elione Maria Nogueira Diogenes (UFAL)

Élsio José Corá (UFFS)

Elizeu Clementino de Souza (UNEB)

Fernando Antônio Gonçalves Alcoforado (IPB)

Francisco Carlos Duarte (PUC-PR)

Gloria Fariñas León (Universidade de La Havana - Cuba)

Guillermo Arias Beatón (Universidade de La Havana - Cuba)

Jailson Alves dos Santos (UFRJ)

João Adalberto Campato Junior (UNESP) Josania Portela (UFPI)

Leonel Severo Rocha (UNISINOS)

Lídia de Oliveira Xavier (UNIEURO)

Lourdes Helena da Silva (UFV)

Marcelo Paixão (UFRJ e UTexas - US)

Maria de Lourdes Pinto de Almeida (UNOESC)

Maria Lília Imbiriba Sousa Colares (UFOPA)

Maria Cristina dos Santos Bezerra (UFSCar)

Paulo Romualdo Hernandes (UNIFAL-MG)

Renato Francisco dos Santos Paula (UFG)

Rodrigo Pratte-Santos (UFES)

Sérgio Nunes de Jesus (IFRO)

Simone Rodrigues Pinto (UNB)

Solange Helena Ximenes-Rocha (UFOPA)

Sydione Santos (UEPG)

Tadeu Oliver Gonçalves (UFPA)

Tania Suely Azevedo Brasileiro (UFOPA)
Angelo Aparecido Priori (UEM)

Arnaldo Oliveira Souza Júnior (UFPI)

Carlos Ugo Santander Joo (UFG)

Dagmar Manieri (UFT)

Edison Bariani (FCLAR)

Elizeu de Miranda Corrêa (PUC/SP)

Fauston Negreiros (UFPI)

Fernando Antonio Gonçalves Alcoforado

(Universitat de Barcelona, UB, Espanha)

Giovani José da Silva (UNIFAP)

José de Ribamar Sousa Pereira (Exército

Brasileiro/Ministério da Defesa)

Kelly Cristina de Souza Prudencio (UFPR)

Liv Rebecca Sovik (UFRJ)

Marcelo Paixão (UFRJ e UTexas - US)

Marcos Aurelio Guedes de Oliveira (UFPE)

Maria Schirley Luft (UFRR)

Mauro Guilherme Pinheiro Koury (UFPB)

Ricardo Ferreira Freitas (UERJ)

Renato Jose Pinto Ortiz (UNICAMP)

Rubens Elias da Silva (UFOPA)

Sergio Augusto Soares Mattos (UFRB)

Silvia Maria Favero Arend (UDESC)

Sonia Maria Ferreira Koehler (UNISAL)

Suyanne Tolentino de Souza (PUC-PR)

Este livro foi avaliado e aprovado por pareceristas ad hoc. 



\section{SUMÁRIO}

APRESENTAÇÃO

MUNDOS DE MULHERES E FAZENDO

GÊNERO - ACADEMIA EM MOVIMENTO

Ana Maria Veiga

Claudia Regina Nichnig

Cristina Scheibe Wolff

Jair Zandoná

\section{GÊNERO E FEMINISMOS}

CAPÍTULO 1

REDES FEMINISTAS NO ENFRENTAMENTO DO

RACISMO PATRIARCAL HETERONORMATIVO

Cláudia Pons Cardoso

CAPÍTULO 2

DUELO, DESOBEDIENCIA Y DESEO

María Pia López

CAPÍTULO 3

DIREITOS REPRODUTIVOS E REPRODUÇÃO ASSISTIDA:

aportes da sociologia do corpo

Laurence Tain

CAPÍTULO 4

COALICIONES QUEER: aborto, feminismo y

disidencias sexuales (1990 a 2005 en Buenos Aires)

Mabel Bellucci

CAPÍTULO 5

GÊNERO E FEMINISMO EM CIÊNCIAS E TECNOLOGIA:

o papel de uma educação crítica

Carla Giovana Cabral

CAPÍTULO 6

NAS PROFUNDEZAS RASAS DO CORPO:

semióticas a-significantes e processos de subjetivação

e dessubjetivação dos marcadores sociais de gênero

Durval Muniz de Albuquerque Júnior

CAPÍTULO 7

CRÍTICA FEMINISTA E NARRATIVAS PÓS/DESCOLONIAIS:

os limites do gênero e da representação

Sandra Regina Goulart Almeida 
CAPÍTULO 8

O DISCURSO OPOSICIONAL E OS

PARADOXOS DA REPRESENTAÇÃO

Leila Assumpção Harris

\section{FEMINISMOS HISTÓRICOS E CONTEMPORÂNEOS}

CAPÍTULO 9

FEMINISMOS, PADRÕES DE ATUAÇÃO E DISPUTAS

POLÍTICAS NO BRASIL CONTEMPORÂNEO

Flávia Biroli

CAPÍTULO 10

LOS RETOS DEL FEMINISMO EN LA ERA DEL "FASCISMO

SOCIAL" Y DEL NEO-INTEGRISMO RELIGIOSO

EN CENTROAMÉRICA

Montserrat Sagot

III. ARTE E GÊNERO: subversões, resistências e afirmatividade

CAPÍTULO 11

EXPOSICIONES DE ARTE FEMINISTAS Y/O DE LO QUEER:

¿resistencias, utopías o arqueologías?

Rosa Maria Blanca

CAPÍTULO 12

MARCHA DOS VADIOS DE ALICE PORTO: apropriações

de fotografias de feministos em manifestações feministas

Ana Maio

CAPÍTULO 13

OCUPAR O ENSINO DE ARTES COM AS REFLEXÕES

SOBRE RELAÇÕES DE GÊNERO E DE SEXUALIDADES

Rafael Siqueira de Guimarães

IV. CORPOS, SABERES, TERRITÓRIOS:

desafios do gênero e da negritude na contemporaneidade

CAPÍTULO 14

SEXUALIDADE, GÊNERO E DISTOPIA NAS LITERATURAS

AFRICANAS DE LÍNGUA PORTUGUESA

Mário César Lugarinho

CAPÍTULO 15

IMITAÇÃO DE SARTRE E SIMONE DE BEAUVOIR OU A

DIFICULDADE DAS RELAÇÕES SOCIAIS E AFETIVAS NO

PÓS-INDEPENDÊNCIA ANGOLANO

Maria Teresa Salgado 
CAPÍTULO 16

CORPOS NUS DE MULHERES NEGRAS:

poéticas da violência / poéticas da resistência

Catarina Martins

CAPÍTULO 17

A ESCRITURA COMO ESPAÇO DE RESISTÊNCIA E PODER:

autoras com origens em ex-colônias italianas na África 185

Márcia de Almeida

CAPÍTULO 18

CORPO, DISCURSO E POESIA EM AUTORAS NEGRAS

CONTEMPORÂNEAS: linguagens eco(dis)tópicas

Izabel F. O. Brandão

\section{FILOSOFIA FEMINISTA NA AMÉRICA LATINA}

CAPÍTULO 19

ALGUNOS APUNTES SOBRE FEMINISMOS EN AMÉRICA LATINA ..... 213

María Luisa Femenías

CAPÍTULO 20

FEMINISMO DIALÓGICO

Márcia Tiburi

CAPÍTULO 21

AATUALIDADE DO FEMINISMO NEGRO E

INTERSECCIONAL DE LÉLIA GONZALEZ

Carla Rodrigues

\section{GÊNERO, DIVERSIDADES E EDUCAÇÃO: perspectivas contemporâneas}

CAPÍTULO 22

A QUEM TUDO QUER SABER, NADA SE LHE DIZ:

uma educação sem gênero e sem sexualidade é desejável?

Fernando Seffner

CAPÍTULO 23

ASCENSÃO E QUEDA DE UMA POLÍTICA EDUCACIONAL LGBT

Alexandre Bortolini

CAPÍTULO 24

GÊNERO E EDUCAÇÃO - A EXPERIÊNCIA DO GDE

Olga Regina Zigelli Garcia 


\section{O CUIDADO COMO UM DIREITO: \\ produção e reprodução da vida humana}

CAPÍTULO 25

INTERFACES ENTRE VIOLÊNCIAS DE GÊNERO E AÇÕES DE CUIDADOS

Lourdes Maria Bandeira

CAPÍTULO 26

GÉNERO, MIGRACIONES Y CUIDADO COMUNITARIO

EN CONTEXTOS DE RELEGACIÓN URBANA

María José Magliano

CAPÍTULO 27

E QUEM VAI CUIDAR DELAS? MIGRAÇÃO

INTERNACIONAL DE MULHERES ORIGINÁRIAS

DA AMÉRICA LATINA E TRABALHOS DE CUIDADO

299

Delia Dutra

\section{PSICOLOGIA, GÊNERO E SAÚDE}

CAPÍTULO 28

GÊNERO E SAÚDE: encrencas transdisciplinares para a psicologia?

Anna Paula Uziel

CAPÍTULO 29

GÊNERO, GERAÇÃO E SAÚDE:

diálogos entre a antropologia e a psicologia

Mónica Franch

CAPÍTULO 30

SAÚDE MENTAL E GÊNERO

Valeska Zanello

IX. GÊNERO E DEFICIÊNCIAS:

dos modelos e representações às múltiplas vivências

CAPÍTULO 31

DIVERSIDADE FUNCIONAL, PORNOGRAFIA

E PÓS-PORNOGRAFIA

Jorge Leite Jr.

CAPÍTULO 32

GÊNERO, DEFICIÊNCIA E A PRODUÇÃO

DE VULNERABILIDADES 


\section{GÊNERO E VIOLÊNCIAS NA AMÉRICA LATINA}

CAPÍTULO 33

AFECTOS JUSTOS: testimonio, violencia y género 365

Claudia Bacci

CAPÍTULO 34

AFECTOS, DUELO Y JUSTICIA EN LAS PRODUCCIONES

VISUALES SOBRE MUJERES PRESAS Y MUERTAS POR

ABORTAR EN AMÉRICA LATINA

Nayla Luz Vacarezza

CAPÍTULO 35

EL GÉNERO Y LA GENERALIZACIÓN DE LA

VIOLENCIA EN EL CONTEXTO MEXICANO ACTUAL

393

Mariana Berlanga

CAPÍTULO 36

MUJERES Y RESISTENCIA: las múltiples guerras

en el marco del conflicto armado colombiano 403

Izabel Solyszko Gomes

\section{RELAÇÕES DE GÊNERO NO MUNDO DO TRABALHO}

CAPÍTULO 37

DIVISÃO INTERNACIONAL DO TRABALHO, PRECARIZAÇÃO

E DESIGUALDADES INTERSECCIONAIS

Helena Hirata

CAPÍTULO 38

LA DESIGUAL ECUACIÓN ENTRE EL GÉNERO

$Y$ EL TRABAJO: perspectivas feministas

Débora D’Antonio

CAPÍTULO 39

TRANSFORMAÇÕES E PERMANÊNCIAS NA TRAJETÓRIA

E ORGANIZAÇÃO DAS MULHERES DA CENTRAL ÚNICA

DOS TRABALHADORES

Junéia Martins Batista

CAPÍTULO 40

A REFORMA DA PREVIDÊNCIA SOCIAL BRASILEIRA

Ela Wiecko V. de Castilho 


\section{MULHERES RURAIS E AGRICULTORAS}

CAPÍTULO 41

QUE FEMINISMO É ESSE QUE NASCE NA HORTA?

463

Maria Ignez Silveira Paulilo

CAPÍTULO 42

METODOLOGÍAS DE CO-CREACIÓN DE CONOCIMIENTOS

PARA LA CONSTRUCCIÓN DEL MEDIO RURAL

LATINOAMERICANO DESDE LAS MUJERES

Ana Dorrego Carlón

\section{INFÂNCIAS, JUVENTUDES E GÊNERO: em debate a interseccionalidade}

CAPÍTULO 43

JÓVENES MILITANTES, SEXUALIDAD Y REVOLUCIÓN:

algunos dilemas en torno a los interrogantes, las categorías y

a la interpretación histórica de los años setenta 485

Isabella Cosse

CAPÍTULO 44

MEDICALIZACIÓN, INFANCIA E INTERSECCIONALIDAD:

historias de vida en Argentina

Cecilia Rustoyburu

\section{GÊNERO, MÍDIAS E REDES SOCIAIS}

CAPÍTULO 45

LAS LUCHAS FEMINISTAS Y LAS PERIODISTAS

CON VISIÓN DE GÉNERO: una articulación indispensable 507

Florencia Laura Rovetto

CAPÍTULO 46

LA ESCUELA AUDIOVISUAL AL BORDE (2011-2016):

políticas de la representación y artivismo contrasexual globalizado

Marta Cabrera

CAPÍTULO 47

CONTRANARRATIVAS NEGRAS E

DE GÊNERO EM MÍDIAS DIGITAIS

Célia Regina da Silva

CAPÍTULO 48

NEOCAPITALISMO EN RED: cuerpos a la carta 



\title{
CAPÍTULO 16 \\ CORPOS NUS DE MULHERES NEGRAS: poéticas da violência / poéticas da resistência
}

\author{
Catarina Martins ${ }^{1}$ \\ "Femme nue, femme noire [...], \\ Je te découvre, Terre promise..." (SENGHOR, 1944)
}

Nos países africanos, em geral, e nos países africanos de língua oficial portuguesa, em particular, o colonialismo encontrou nos corpos nus das mulheres negras um instrumento concreto e retórico axial para o exercício material e simbólico das mais extremadas práticas de poder. Tendo como objeto a(s) mulher(es), reais ou metafóricas, estas práticas destinavam-se, sobretudo, à dominação dos homens brancos sobre os homens negros, segundo uma lógica em que as corporalidades eram discursivamente construídas para sustentar uma hierarquia civilizacional e legitimar a imposição de uma ordem social codificada segundo os eixos de género e de raça. De facto, para lá da linha abissal que separa colonizador de colonizado, um espaço onde, como afirma Sousa Santos (2007), só são válidas as lógicas da apropriação e violência, estas não são exercidas de forma homogénea. A ordem social sexuada do mundo colonizador é transferida, por imitação, para o mundo colonizado, no qual, como constata Lugones (2010), não havia "homens vs mulheres", mas apenas "machos vs fêmeas". Desta forma, constrói-se uma hierarquia na qual as mulheres, meros corpos negros e nus, foram levadas ao extremo do despojamento que permite a máxima apropriação, por todos os agentes de uma complexa rede de relações de poder, incluindo os próprios homens negros. Se estes homens também eram corpos aos dispor do colonizador, possuíam ainda a capacidade de expressão de posse sobre as suas mulheres. Nos corpos de fêmeas negras, a nudez aparece como a própria inscrição da alienabilidade, ou seja, trata-se de corpos que são definidos por um constante "não-ser", manifesto na disponibilidade de utilização por parte de outrém, através de diferentes modos de exploração, do trabalho, ao sexo e à reprodução. O modo de "haver" destes não mais que corpos nus é, por conseguinte, o modo da negação e da violência. Assinale-se que, na retórica lusotropicalista que sustenta o império português em particular, o enaltecimento da mestiçagem mais não é do que o elogio da licença para violar.

$1 \quad$ Professora Auxiliar do Departamento de Línguas, Literaturas e Culturas da Faculdade de Letras da Universidade de Coimbra e Investigadora do Centro de Estudos Sociais. E Doutorada em Literatura Alemã pela Universidade de Coimbra (2008). Tem publicado sobre temas de estudos feministas e pós-coloniais, literatura comparada, literatura de expressão alemã e literaturas africanas, em particular de mulheres. De entre as suas actuais áreas de investigação destacam-se os estudos pós-coloniais e os estudos feministas, associados a temas e problemáticas das literaturas e culturas. E-mail: cmartins@ci.uc.pt 
Os corpos femininos, negros e nus aparecem, ainda, como eixo estruturante do discurso que sustenta esta ordem política colonial, constituindo o nó de um repertório simbólico e de uma gramática adaptáveis aos diferentes contextos em que, literalmente ou por analogia, é necessário firmar relações de poder assentes na intersecção de raça e género. Assim, a terra africana, virgem, núbil e fértil, que se oferece ao colonizador, aparece como o corpo feminino apropriável, sobretudo devido à exuberância selvagem e ao excesso sensual da sua Natureza. Estes atributos, por sua vez, são conferidos às mulheres negras, como Evas arquetípicas num heart of darkness que seduz inexoravelmente e ameaça, devendo, pois, ser domado. A estrita corporeidade destas fêmeas, no quadro do caos irracional dos territórios selvagens, forma o contraponto com a incorporeidade das mulheres brancas, paradoxalmente associadas a uma espiritualidade virtuosa e à pureza de Maria, mesmo na qualidade de mães. Esta oposição permite diferenciar os frutos de ventres brancos e negros, mesmo quando produto do mesmo sémen (uns, humanos; outros sub-humanos), licencia a opressão de mulheres negras por mulheres brancas, e responsabiliza as negras pelas sistemáticas violações. A gramática da diferença sexual serve, também, discursivamente a caracterização do negro, ora efeminado, quando interessa destacar a inferioridade em relação ao homem branco, cuja espingarda, a tecnologia, constitui um falo mais potente do que qualquer arma primitiva, ora hipersexualizado, quando interessa sublinhar a sua natureza selvagem, que a missão civilizadora deve neutralizar. Neste último caso, a apropriação da mulher negra por parte do homem branco chega a aparecer retoricamente como um acto bondoso de proteção daquela em relação à violência do negro. Na realidade, o que se pretende com este acto é a aniquilação do negro pela humilhação que constitui a ocupação violenta da "sua" mulher, numa contenda masculina em que a mulher serve apenas de objeto de disputa, cujo sofrimento não é sequer considerado. Assim, os corpos de mulheres negras fornecem o conjunto de atributos que permitem configurar discursivamente mesmo as relações de poder entre homens, brancos e negros, ou do homem branco sobre a mulher branca. Desta forma, mesmo que sempre ausentes no seu "não-ser", estes corpos possuem uma materialidade extremamente densa e ubíqua na poética e na política do colonialismo, a qual é sempre uma escrita e uma prática da violência nas formas mais extremas.

O facto de a lógica de apropriação e violência, manifesta no outro lado da linha abissal do colonialismo, ser diferenciada em termos de género torna-se claro quando atentamos nos projetos anticoloniais e das independências. Neste contexto, em que a cultura é mobilizada para consubstanciar ideias de nação e se torna crucial para a mobilização de uma ideia de povo, em particular nos anos que precederam e durante a luta armada, as noções de origem, de autenticidade, de tradição, são evocadas a partir de um reportório simbólico e poético associado à Mulher, consonante com a construção mítica da responsabilidade do movimento da Negritude. O poema "Femme Noire" (1944), de Léopold 
Sédar Senghor (Senegal), é o epítome da figuração da África num corpo negro e nu de mulher, Terra-Mãe-origem protectora e fecunda, ou terra-sensualidade arquetípica, cujas curvas e texturas reproduzem as paisagens de um território a ser possuído e fecundado pelo homem (BOEHMER, 2005, p. 24). Os homens são os sujeitos que escrevem, pelejam, se erguem virilmente como herois sobre um objeto - o mesmo território-corpo feminino que o colono também cantara e possuíra. No discurso masculino, a Mulher mítica fornece um corpo (corpus) metafórico a uma poética de violência que sustenta as dominações sucessivas exercidas sobre as mulheres africanas. Mais do que isso: a exploração das mulheres reais chega a ser celebrada enquanto essência africana (e, portanto, naturalizada e não transformável): a da mulher rural da maternidade sucessiva e sacrificada, das cargas transportadas à cabeça e do filho amarrado às costas, da tradição etnicizada e de uma temporalidade primitiva, da ignorância, da oralidade, das línguas locais, uma mulher excluída das linguagens e das práticas da modernidade. De facto, é discursivamente criada uma dualidade sexuada, que permite ancorar a identidade nacional africana em tempos remotos, através das representações do feminino e, simultaneamente, apresentá-la como protagonista de uma modernidade urbana, através das representações do masculino como o Homem Novo do discurso marxista, que se propagou em Angola e em Moçambique, os casos de que aqui me ocuparei. Este Homem Novo, supostamente desetnicizado e sem sexo e, por isso, igualitário, servirá como base política para a conceção de um corpus jurídico que configura uma cidadania moldada pelo masculino e consagra a supremacia dos homens nos direitos e nas práticas sociais. Assim, no contexto da libertação do colonialismo, mais uma vez, os corpos nus de mulheres negras são manuseados como um instrumento discursivo fundamental de um poder que agora é negro, mas permanece masculino e patriarcal, e que igualmente os objetifica, domina, expropria, controla e violenta. A linha abissal última desloca-se, assim, para a fronteira entre homens negros e mulheres negras.

Este facto torna-se claro na literatura que desempenhou um papel fulcral nas independências africanas. De facto, desde o poema já evocado de Senghor ao romance emblemático do anticolonialismo africano - ThingsFall Apart -, do nigeriano Chinua Achebe, é evidente um paradigma que reforça as masculinidades africanas à custa de um papel subalterno para as mulheres. Estas são obras canónicas, legitimadas pela crítica literária e pela historiografia pelo seu valor nacionalista, que quase nunca dá atenção à forma como é naturalizada a violência exercida sobre as mulheres pelos herois negros, como uma espécie de fator inerente às próprias vitórias sobre o colonizador. $\mathrm{O}$ exemplo maior nas literaturas lusófonas é, talvez, Pepetela. Em romances como Mayombe ou A Geração da Utopia, a apropriação do corpo feminino através da violação sexual surge recorrentemente sob uma óptica idealizada que jamais perturba a legitimidade moral dos heróis ou até a alimenta. O corpo feminino existe em 
função do guerreiro ou converte-se na natureza em que este mergulha para renovar as forças indispensáveis para o combate pela nação.

Este facto extraordinário tem de constituir um apelo fortíssimo a uma autorreflexão dos estudos que se ocupam das literaturas africanas, os quais necessitam de uma revisão profunda travejada por perspetivas feministas. Devemos interrogar não somente as ausências de vozes femininas, mas os próprios modelos epistemológicos androcêntricos que sustentam a hermenêutica textual. Estes convertem a crítica literária em agente ativo destas ausências, validando um cânone e uma periodização em que as vozes femininas, enquanto sujeito, não podem ter lugar. Ou seja, enquanto as mulheres permanecerem adstritas ao "não-ser" de corpos nus, disponíveis como material poético para a dominação masculina, o seu lugar na escrita será também um "não-lugar" ou um lugar eternamente marginal - a prateleira da "literatura de autoria feminina" (MATA, 2015, p. 24), identificada apenas a partir dos anos 80 do séc. XX, e caracterizada da seguinte forma:

[...] estes títulos revelam, à partida, uma diferente perspetiva, esta subjetiva, porque vivencial e intimista [...]. As vozes femininas da actualidade, não descurando a dimensão comunitária, já prenunciam uma busca individual, mais íntima e sonhadora, mesmo quando a sua preocupação última é colectiva... (MATA, 2007, p. 425).

A colagem das literaturas africanas, por parte da crítica, a um fazer histórico de ordem política e pública, construído discursivamente em moldes androcêntricos, bem como, por vezes, às ideologias dos processos de construção nacional, tem importantes consequências. De um ponto de vista feminista, que entende que o "privado é também público", bem como do ponto de vista pós-colonial, que percebe a noção de "privado" como uma herança colonial ocidental, distinta das mundivisões mais fortemente comunitárias das culturas africanas, é difícil compreender uma separação entre uma escrita do coletivo (masculina), e uma escrita intimista, do individual ou do "corpo amoroso" (feminina). Acresce que a própria ideia de História em que o estudo das literaturas africanas assenta é estruturada sobre pilares epistemológicos ocidentais que as expressões culturais africanas tradicionalmente contrariaram: desde logo, uma noção linear e teleológica de tempo, em que o passado tem menos peso do que, por exemplo, os cultos da ancestralidade, no âmbito de temporalidades circulares ou de espaços/tempo que se interpenetram; a preocupação com a factualidade e a menor atenção ao universo mítico, com a correspondente focalização em territórios materiais, e não em espaços imaginados, nómados, híbridos; a História como sucessão de linhas de conflito geralmente dicotómicas (colonizador / colonizado; branco / negro), e de eventos políticos e guerreiros, entre outros. A esta construção da História e da nação, em particular em países como Angola e Moçambique que sofreram duas longas guerras, corresponde toda uma gramática masculina da violência, estruturada em torno de herois e mártires masculinos e valores másculos como 
a força, a valentia, a resistência, validando-se lugares de memória associados às conquistas da força ou ao tombar do corpo masculino.

O corpo de mulher, negro e nu, surge, pois, como o elemento central de uma poética da violência que sustenta discursivamente toda uma estrutura de dominação masculina. As mulheres escritoras africanas reconhecem claramente este facto e convertem o mesmo corpo no eixo de poéticas da resistência, invertendo, desde logo, o objeto que é escrito (possuído, dominado) no sujeito que escreve. $\mathrm{O}$ confronto intertextual e a reescrita da poética masculina, que passa, inevitavelmente, pela reescrita da própria violência a partir de uma posição radicalmente outra, constituem, assim, um momento essencial para o resgate e a reivindicação desse corpo, e para a reinscrição das mulheres numa História e num corpo nacional através de narrativas com protagonistas e topoi completamente distintos. A título de exemplo, cito dois poemas de Ana Paula Tavares e Ana de Santana (Angola) e alguns elementos dos romances Niketche. Uma História de Poligamia (2002) e O Alegre Canto da Perdiz (2008), de Paulina Chiziane (Moçambique). Estes textos constituem uma disputa pelo espaço, pelo tempo, e por um dizer do coletivo no sentido de, justamente, rever as linhas semânticas e as lógicas discursivas androcêntricas e ocidentais (e, nesse sentido, coloniais) da História e da identidade angolana e moçambicana. Estas escritoras partem de uma ressignificação do corpo feminino e negro, ostentando a nudez como forma de negar a sua expropriação e objetificação. Os corpos das mulheres aparecem como arma de cisão de corpora institucionalizados (o corpo nacional, o corpus do cânone literário, os corpos emblemáticos de papéis sociais normativos), de modo a criar fissuras em que se inscrevam camadas de espaços concomitantes e de tempos coevos, até aqui silenciados e ocultados.

Começo por Paula Tavares e o seu primeiro livro, Ritos de Passagem (1985), o qual interpreto como uma proposta de reinscrição do corpo feminino e negro no "ser" real e no tempo. De um modo que só aparentemente se reduz à expressão de anseios e desejos individuais, Tavares revela, afinal, que este corpo sensualizado foi e é o próprio território do político. Em Alphabeto (TAVARES, 2007, p. 58), o eu lírico identifica claramente o corpo feminino como constante produto de uma escrita alheia, ciclicamente recomposto. A dactilografia, um percorrer táctil da pele-superfície de escrita, é só aparentemente libertadora. As asas que esta reescrita abre não permitem superar inscrições anteriores, fazendo surgir uma pluralidade de cicatrizes. Trata-se de um corpo-palimpsesto-objeto, ainda entregue às mãos de um "tu" que, no poema "Desossaste-me" (TAVARES, 2007, p. 54), é evocado num tom de acusação pela dimensão de violência inerente à recomposição escrita. Esta desenvolve-se como atos sucessivos de desmembramentos e inscrições num universo Outro ao sujeito da enunciação - o universo masculino -, em relação ao qual o corpo feminino representa um conjunto de antíteses: ferida e prótese, maldita e necessária. O texto decorrente desta inscrição é inexoravelmente aquele que serve uma totalidade construída 
pelo masculino, que se instituí como teleologia do feminino, reduzindo-o a um estatuto de "não-ser". Até que, num momento muito forte de rutura, o corpo feminino completo e vivo (aceso), que usa os próprios instrumentos de inscrição (tacula), recusa o papel subserviente materializado nas tarefas domésticas e na reclusão e reclama, em maiúsculas, a voz incisiva, o poder de decisão, a sua libertação e um estatuto de sujeito.

Enquanto o primeiro poema parece remeter para um tempo iterativo inexorável de alienação do corpo feminino exposto à inscrição de violências repetidas, o segundo opera uma cisão nesta continuidade temporal e espacial do universo-Todo-homem, reclamando para o Eu enunciador um momento iniciático e uma geografia própria. O tempo é também iterativo, mas no sentido da repetição contínua do gesto de emancipação. Em ambos os poemas, o corpo e o sentir não são meramente individuais nem evocam apenas o coletivo das mulheres. Acima de tudo, confrontam as estruturas discursivas patriarcais da construção cultural, as suas axialidades espácio-temporais, e a desmaterialização do corpo feminino, negro e nu numa mitificação que serve o poder patriarcal. De resto, o conjunto do volume desenvolve-se sob o signo da "passagem" para uma outra escrita do corpo já nem feminino nem masculino, em que as metáforas são despidas da semântica rígida que possuíam no corpo retórico da "africanidade" para se abrirem a deslocamentos e transformações num espaço sempre transicional e de tradução. Os sangues vertidos pelas mulheres (menstruação, desvirgindação, parto, violação), por exemplo, passam a ocupar o lugar central em "cerimónias de passagem" que asseguram a unidade cultural num tempo elíptico, substituindo-se aos sangues dos heróis homens conquistadores num tempo linear. Como no poema de Ana de Santana, intitulado "Canção para uma Mulher", incluído em Sabores-Odores \& Sonho (1985), em que o dizer do corpo feminino é um canto silenciado de uma "música estuprada à força do falo" (GIOVETH; SANTOS, 2005, p. 39) e o ato de fecundação é atribuído a mulheres sem homem, um momento fundacional que carece ainda de bocas femininas libertas e de filhos que inscrevam o corpo feminino, não como recetáculo, mas como verdadeiro agente do ato de criação, mesmo quando este resulta do "estupro" que metonimicamente designa toda a violência real e simbólica exercida sobre o corpo das mulheres. De resto, no poema "Ralhete" (GIOVETH; SANTOS, 2005, p. 38), que inscreve habilmente a guerra num espaço onde público e privado não se distinguem, não encontramos apenas a voz de uma mãe que admoesta severamente o filho que reclama dela funções maternais tradicionais, mas a interpelação de todo um horizonte de expetativas relativamente ao que é a mulher-mãe-África, em particular num contexto de conflito que problematiza as identidades estruturantes da unidade nacional construída na literatura patriarcal. O corpo feminino enquanto tropo é, mais uma vez, decomposto em partes que recusam o papel servil que exerciam na construção ideológica masculina. A cisão com esta construção é localizada, expressamente, na apresentação do ato da fecundação como violação, que impede 
a concretização da maternidade nos termos que a deviam definir. $\mathrm{O}$ Eu feminino que afirma que "a minha boca / há muito se fechou à força / do fuzil do homem / que em mim te semeou" é, paradoxalmente, neste registro de "Ralhete", uma voz fortíssima, em que dor é indissociável de resistência, vontade e decisão. Um sujeito, e nunca uma vítima.

Portanto, estas poetas questionam, com a sua escrita, não apenas o que é narrado no corpus da cultura, mas o modo da narrativa, os seus topoi, e as posições de sujeito / objeto, agente / paciente, os tempos e os espaços que nela se concretizam. Atente-se neste belíssimo passo de Niketche (2002), de Paulina Chiziane:

Nós, mulheres, fazemos existir, mas não existimos. Fazemos viver, mas não vivemos. Fazemos nascer, mas não nascemos. Há dias conheci uma mulher do interior da Zambézia. Tem cinco filhos, já crescidos. $\mathrm{O}$ primeiro, um mulato esbelto, é dos portugueses que a violaram durante a guerra colonial. $\mathrm{O}$ segundo, um preto, elegante e forte como um guerreiro, é fruto de outra violação dos guerrilheiros de libertação da mesma guerra colonial. O terceiro, outro mulato, mimoso como um gato, é dos comandos rodesianos brancos, que arrasaram esta terra para aniquilar as bases dos guerrilheiros do Zimbabwe. O quarto é dos rebeldes que fizeram a guerra civil no interior do país. A primeira e a segunda vez foi violada, mas à terceira e quarta entregou-se de livre vontade, porque se sentia especializada em violação sexual. O quinto é de um homem com quem se deitou por amor pela primeira vez.

Essa mulher carregou a história de todas as guerras do país num só ventre (CHIZIANE, 2002, p. 277-278).

Desta forma concentrada, Chiziane reconta a História nacional a partir dos corpos das mulheres. Estas são geralmente excluídas não somente da noção heroica de combatentes, da resistência persistente do quotidiano da retaguarda, como até da história da dor. Mártires são os homens que tombam, mas nunca mulheres como esta, que Chiziane resgata. O corpo negro desta mulher tem gravada em si a História do seu país, onde as mulheres são a substância e a permanência numa inconstância de homens. O corpo negro deixa de ser metáfora e a mitificação é anulada através da crueza de uma realidade excessivamente violenta. Para além disso, não se mostra uma mulher vítima. $O$ conceito de vítima é ressignificado na forma como a mulher recupera a propriedade e a capacidade de ação do seu corpo usurpado e se torna criadora de uma nova raça por actos de resistência e amor. Esta raça moçambicana é inevitavelmente mestiça, pois os conflitos da história nunca resultam em separação, mas em histórias misturadas que jamais conseguirão dissociar-se. A História não é uma linha só com um fim único, mas uma trama materializada nos corpos e pelos corpos de mulheres em que linhas convergem, se cruzam e divergem, perfazendo uma cartografia complexa, paradoxal.

Uma intenção semelhante à do passo citado de Niketche é a que vemos desenvolvida em O Alegre Canto da Perdiz, que conta a História de Moçambique 
da perspetiva de três mulheres de três gerações da mesma família, do período colonial, passando pelas guerras e construindo a utopia de um país pacificado e conciliado. A narrativa começa com a aparição inusitada de uma mulher negra e nua, junto dos montes Namuli, na província da Zambézia, que são associados à origem do mundo. De seguida, o romance desenvolve-se em dois planos. Um deles é uma série de lendas que reescrevem o domínio do mítico, em paralelo com o da História, numa ótica de mulheres heroicas. A Zambézia, metonímia de Moçambique, é retratada como feminina, uma terra fértil cobiçada pelos "marinheiros" - os colonizadores brancos. Se se mantém a típica associação da mulher à terra africana, a construção de Moçambique aparece, porém, como uma contenda sexuada, um paradoxo de desejo e violência, prazer e dor, cujo centro e agente são as mulheres. Os seus corpos violentados, como no poema de Ana de Santana, são o lugar sofrido da criação de "uma nova raça". Também os corpos femininos vertem sangues, mas a sua heroicidade assenta numa ação criadora e unificadora radicalmente inversa ao ato masculino, destruidor e traidor. O erotismo e a sensualidade femininos e masculinos surgem como uma vivência coletiva, como forças moventes da História, e não como expressão de um desejo subjetivo:

De todas as sereias, a Zambézia era a mais bela. Os marinheiros invadiram-na e amaram-na furiosamente, como só se invade a mulher amada. A Zambézia bela, encantada, gritava em orgasmo pleno: vem, marinheiro, ama-me, eu te darei um filho. Eu e tu, sempre juntos, criando uma nova raça. [...] Os navegadores correram de aldeia em aldeia, derramando sangue, profanando túmulos, pervertendo a história, fazendo o impensável. A Zambézia abriu o seu corpo de mulher e engravidou de espinhos e fel. [...] Havia lógica em tudo aquilo. O homem apaixonado tudo arrasa para possuir a mulher amada. É a vida. Primeiro o prazer do amor, na gestação da dor. Com enjoos e vómitos para temperar a gravidez. $\mathrm{O}$ corpo transformado, rasgado, ferido. $\mathrm{O}$ sangue fluindo, no parto da nova nação (CHIZIANE, 2008, p. 64).

O outro plano diegético é uma enorme analepse que conta o passado de Maria das Dores, o corpo nu exposto na abertura do romance. Maria das Dores é vendida pela mãe, sofre os maus-tratos do marido num lar polígamo e foge, levando os filhos pequenos que perde num Moçambique em guerra. É, como a mulher de Niketche, um corpo prostituído, violentado, de muitos sangues. É um mapa físico, traçado por cicatrizes, de uma deambulação solitária e desesperada pelo território do país, numa procura pelos filhos que é também a procura pela identidade de um povo. Maria das Dores contradiz e complexifica as representações típicas da mulher africana: mãe que dá à luz, mas cuja maternidade é o martírio de um ventre e um coração expoliados pela perda daqueles que gerou; corpo nu, mas não virgem, nem núbil - um corpo repetidamente penetrado, libertado paradoxalmente pelo sofrimento extremo. Um corpo que transporta um poder de transformação obriga a um olhar novo sobre conflitos, divisões e caos: 
Colocámos os pretos e os brancos na batalha das raças, mas eles tanto se bateram até que se beijaram. E se apaixonaram pela bravura de um e de outro. Acabaram casados, numa só paixão, formando uma só família [...]. No final desta guerra seremos um. Esses filhos metade pretos, metade brancos, metade asiáticos, serão os fósseis a partir dos quais se compreenderá a nossa História. Nas próximas gerações as raças se amarão, sem ódio nem raivas, inspiradas no nosso exemplo. [...] Terá chegado o momento de inventar novas raças e recriar novas humanidades (CHIZIANE, 2008, p. 333-334).

Com esta conclusão, Chiziane faz uma reavaliação da História em que os heróis e as valentias são perspetivados com matizes vários. Procede-se à reinscrição das mulheres no papel de criadoras, cujos corpos são entendidos como armas e locus de combate, e cujos sangues - das violações e dos partos - são reconhecidos como sangues igualmente vertidos pela pátria. Esta reinscrição é colocada em oposição à destruição motivada pelo ímpeto de conquista violenta de colonizadores e resistentes anticoloniais, materializado nas guerras sucessivas. Para além disso, o corpo feminino negro e nu, aparecido junto dos montes Namuli, a que o romance regressa no final como um colo materno original, converte-se no momento utópico de unidade nacional, através da criação de uma identidade mestiça para Moçambique.

A subalterna, a quem foi negada voz, disputa um espaço de fala, para contar as experiências vividas pelas mulheres, a especificidade das opressões e violências que sofreram no colonialismo, no processo de constituição dos novos países e na pós-colonialidade. Os seus corpos deixam de ser metáfora para se mostrarem de uma forma muito assertiva como um terreno de disputa no qual o poder e a violência se inscreveram sempre de forma profundamente material. As mulheres que escrevem tornam claro que estas sujeitas nunca foram passivas, tendo, pelo contrário, desenvolvido estratégias várias de resistência e de afirmação que obrigam a uma leitura muito mais complexa dos processos históricos do colonialismo e das independências do que a matriz teleológica e heroica androcêntrica do Novo Homem africano. As estruturas e dinâmicas sociais e políticas dos territórios africanos colonizados e dos países independentes surgem, nas obras escritas por mulheres, como mais intrincadas, com cruzamentos e camadas insuspeitados, nomeadamente por factores raciais e sociais se intersectarem com variadas dimensões sexuadas. Neste reclamar da História por parte das escritoras africanas, os corpos femininos, negros e nus erguem-se e obrigam a uma nova compreensão de si, de quem os oprimiu, e das relações entre ambos. Obrigam, finalmente, a uma nova perceção e a uma nova linguagem para uma narrativa Outra da História e da memória nacionais, em que se deslocam a semântica e o valor de conceitos estruturantes como opressão, submissão, conquista, heroísmo e sangue. A matéria simbólica da qual se constrói a nação será só aparente a mesma e, no entanto, radicalmente invertida. 


\section{REFERÊNCIAS}

BOEHMER, Elleke. Stories of Women. Gender and Narrative in the Postcolonial Nation. Manchester and New York: Manchester UP, 2005.

CHIZIANE, Paulina. Niketche. Uma História de Poligamia. Lisboa: Caminho, 2002.

. O Alegre Canto da Perdiz. Lisboa: Caminho, 2008.

GIOVETH, Filomena; SANTOS, Seomara. O Amor Tem Asas de Ouro. Antologia da Poesia Feminina Angolana. Luanda: UEA, 2005.

LUGONES, Maria. Toward a Decolonial Feminism. Hypatia, v. 25, n. 4, p. $742-759,2010$.

MATA, Inocência. A Literatura Angolana entre Utopias e Distopias: Um Percurso. Textos e Pretextos, Lisboa, n. 19, p. 9-26, 2015. (Angola. Poesia e Prosa)

. Mulheres de África no Espaço da Escrita: A Inscrição da Mulher na

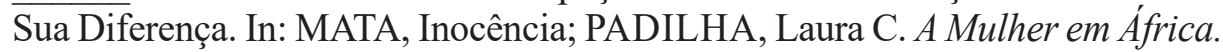
Vozes de uma margem sempre presente. Lisboa: Colibri, 2007. p. 421-440.

OWEN, Hilary. Mother Africa, Father Marx. Women's Writing of Mozambique 1948-2002. Lewisburg. Bucknell University Press, 2007.

SANTOS, Boaventura de Sousa. Para além do Pensamento Abissal: Das linhas globais a uma ecologia de saberes. Revista Crítica de Ciências Sociais, n. 78, p. 3-46, outubro 2007.

TAVARES, Paula. Ritos de Passagem. Lisboa: Caminho, 2007. 